\title{
Variations
}

Variations Revue internationale de théorie critique

$13 / 14 \mid 2010$

Le choix du petit

\section{Le choix du petit}

Editorial

\section{(2) OpenEdition}

Journals

Édition électronique

URL : http://journals.openedition.org/variations/167

DOI : 10.4000/variations. 167

ISSN : 1968-3960

Éditeur

Les amis de Variations

Édition imprimée

Date de publication : 31 mars 2010

Référence électronique

"Le choix du petit », Variations [En ligne], 13/14 | 2010, mis en ligne le 01 février 2012, consulté le 22 septembre 2020. URL : http://journals.openedition.org/variations/167 ; DOI : https://doi.org/10.4000/ variations. 167

Ce document a été généré automatiquement le 22 septembre 2020.

Les ami•e•s de Variations 


\section{Le choix du petit}

\section{Editorial}

\section{NOTE DE L'ÉDITEUR}

Numéro coordonné par Lucia Sagradini, Julien Bordier, Alexander Neumann

Première publication sur www.theoriecritique.com, « Le choix du petit », Printemps

2010, pp. 3-6

1 "Le choix du petit », titre-phare de ce numéro, est venu de la lecture de la postface de Minima Moralia (Payot) écrite par Miguel Abensour. Cet éditorial, lui, a surgi du désir de rendre encore une fois visible le travail d'une revue telle que Variations.

2 Ce travail se signale par une action de concert. Ensemble, nous avons écrit et pensé sur cette question du petit pour vous, lectrices et lecteurs.

3 À chacun-e des auteurs, nous avons demandé une phrase pour illustrer ce que «le choix du petit » leur évoque. À la lecture de chacune des phrases qui suivent, il devient clair que tous ont pris un chemin singulier pour répondre à cette demande. Des réponses souvent chargées de métaphores et de paraboles.

4 Ce numéro s'est déployé, conçu comme un de ces personnages hybrides et enchantés, une femme à pattes de lion, au buste ailé et à queue de licorne. Variations a su prendre de tous les éléments d'une pensée singulière et s'est composée dans la rencontre de leur salutaire hétérogénéité. Car agir de concert ce n'est pas unifier les idées, mais bien plus les unir dans une lutte et un projet commun.

5 Rester soi et faire une place à l'autre, tout en construisant un territoire étranger et commun à chacun.

6 Les formes hybrides, chimères et monstres, si récurrentes au Moyen Âge ouvrent la voie à un monde où tout est possible. Ce numéro 13/14 de Variations cherche à planer sur l'ordre du monde avec cette ambition d'offrir d'autres chemins.

$7 \quad$ En voici le cadavre exquis 
8 John Holloway Le petit parce que nous sommes petits et l'on doit commencer de là où l'on est, maintenant. Mais un petit qui ne connaît pas de limite, qui déborde et s'écoule dans et avec. Dignité.

9 Mikkel Bolt Rasmussen Dans cette situation où nous nous trouvons, au cœur d'une tentative accélérée pour contrôler les mouvements de la mondialisation, il pourrait s'avérer utile d'examiner les tentatives antérieures où des artistes ont utilisé l'art comme un instrument pour aborder les problèmes sociaux et comme un outil pour intervenir dans le débat public.

10 Greil Marcus Je commence toujours avec quelque chose de petit, puis je trace des cercles autour. Parfois, je reviens vers le centre, parfois non.

11 Julien Bordier Choisir le petit relève du défi. Paradoxalement. Il est proche, presque palpable, à l'intérieur et autour de nous-même. Pourtant il est inattendu, invisible et souvent indicible. Ce défi est autant épistémologique que politique. Son enjeu est grand.

12 Jean-François Gava Le petit est le proche, ce qui est à portée, à mesure de l'homme ; la maîtrise du lointain, du grand que vise la mathématisation du monde comme de ce qui échappe aux sens est le propre de la civilisation anti-technicienne, machinique de la modernité. Le petit, le proche, est ordonné à l'autonomie ; le grand, le lointain, à l'esclavage.

13 Nicolas Poirier Penser la possibilité de l'émancipation n'implique pas qu'il faille nécessairement référer celle-ci à une méta-conception théorique. C'est au contraire en se libérant du fantasme d'une théorie surplombant le réel qu'on peut concevoir une politique cherchant à tracer les voies d'une démocratie radicale. Faire le choix du petit revient ainsi à penser avec Castoriadis la dynamique révolutionnaire comme un processus créatif, où les luttes quotidiennes, loin de ne valoir que comme de microrésistances locales, dessinent les contours d'une politique toute entière tournée vers le refus de la servitude volontaire.

14 Alexander Neumann

Une absence, une béance, un split, Un creux dans un trou, un vide sidéral,

De l'air dans la tête, un manque total

D'élan, de charme et de personnalité.

Le joli fleuron se recrute au milieu

Des cassés, des brimés, des ratés de la vie,

Des cathos schatos, des crétins sectaires,

Bref : parmi les gens ordinaires.

15 Daniel Veron C'est un petit bout de papier. Où c'est écrit en tout petit, avec une petite date, une petite photo. Il parait si petit, ce petit bout de papier. Pourtant quand tu l'as pas, on te met dans des grands centres. Où quand ça brule ça fait de grandes flammes.

Stéphane Le Lay Dialoguer avec les petits, c'est nécessairement prendre une position éthique sur les modes de catégorisation et la normativité des formes de légitimation du social. On peut, par le mépris ou l'indifférence, refuser ou dénier toute grandeur à ce que l'on perçoit de loin comme sans importance. Ou alors essayer de se déprendre des classements matériels et symbolique dominants pour relayer d'autres pratiques, d'autres points de vue, tout aussi signifiants. 
17 Josef Reindl Pour l'individu souverain qui est né de la modernité, l'idée même de la décomposition et de la mort est un affront. Considérer que le crépuscule de la vie, et la mort, puisse contenir un sens, ce qui signifie de donner une forme significative à la dernière période de sa vie, cela fait aujourd'hui partie des défis majeurs auxquels se voit confrontée l'humanité. La modernité tardive n'a pas prévu de scénario pour cette situation, ce qui est la raison pour laquelle l'âge pose problème.

18 Frank Jablonka Il s'ensuit ainsi la nécessité d'une orientation à contre-courant permanent dans le quotidien, y compris contre soi-même, contre les idées reçues, contre le système introjecté, l'État que nous portons, nous tous, en nous, et, bien sûr, contre la tentation à la résignation, à la trahison de soi-même et des proches. Pour être crédibles et convaincants en tant que porteurs d'une pédagogie de rupture, il est nécessaire que la rupture soit consommée au sein des subjectivités.

19 Hélène et José Chatroussat Chute d'Icare. Il voit s'approcher les eaux froides. Il tombe. Ces eaux atroces, elles sont encore si loin. Mais sa chute est verticale, à la perfection. Sur la rive transpire le travailleur. Il se concentre sur sa douleur. Il se referme sur son destin gâché. Il ne voit pas le militant-Icare qui a perdu ses ailes. Il ne sait pas encore que son drame est aussi le sien. 